\title{
Avaliação da penetração de cloretos em concretos imersos em água do mar por meio da aspersão de nitrato de prata
}

\author{
J. V. Tito ${ }^{1 *}$, F. G. S. Silva ${ }^{2}$ \\ *Autor de Contato: joaovictortito@hotmail.com \\ ${ }^{1}$ Escola Politécnica, Universidade Federal da Bahia, Salvador, Brasil \\ ${ }^{2}$ Departamento de Construção e Estruturas, Escola Politécnica, Universidade Federal da Bahia, Salvador, Brasil
}

\begin{abstract}
RESUMO
Este trabalho teve como objetivo avaliar a profundidade da frente de penetração de cloretos em concreto de cimento Portland com diferentes relações água/cimento. Para tanto, foi utilizado o método colorimétrico por aspersão de nitrato de prata, desta forma, foram confeccionados em laboratório e de acordo com as normas, corpos de prova e posteriormente esses corpos de prova foram curados ao ar e então imersos em água do mar, num recipiente dentro do laboratorio. Os resultados foram uma frente de cloretos menor no concreto com menor relação água/cimento. Conclui-se, que quanto menor a relação água/cimento menor a profundidade de penetração de cloretos em função do tempo, resultados esperados, visto que, a relação água/cimento influencia diretamente a microestrutura do concreto.
\end{abstract}

Palavras-chave: cloretos; concreto; método colorimétrico; água do mar; corrosão. 


\title{
Evaluation of chloride penetration in concrete immersed in seawater through silver nitrate spray
}

\begin{abstract}
This work aimed to evaluate the depth of the penetration front of chlorides in Portland cement concrete with different water/cement ratios. For this purpose, the colorimetric method by spraying silver nitrate was used, thus, they were made in the laboratory and according to the standards, specimens and later these specimens were air-cured and then immersed in sea water, in a container inside the laboratory. The results were a lower chloride front in concrete with a lower water/cement ratio. It is concluded that the lower the water/cement ratio, the lower the penetration depth of chlorides as a function of time, expected results, since the water/cement ratio directly influences the microstructure of concrete.
\end{abstract}

Keywords: chlorides; concrete; colorimetric method; seawater; corrosion.

\section{Evaluación de la penetración de cloruros en hormigón sumergido en agua de mar mediante pulverización de nitrato de plata}

\section{RESUMEN}

Este trabajo tuvo como objetivo evaluar la profundidad del frente de penetración de cloruros en hormigón de cemento Portland con diferentes relaciones agua/cemento. Para ello se utilizó el método colorimétrico mediante aspersión de nitrato de plata, por lo que se elaboraron en el laboratorio y del acuerdo a los estándares, las probetas y posteriormente estas probetas se curaron al aire y luego se sumergieron en agua de mar, en un recipiente dentro del laboratorio. Los resultados fueron un frente de cloruro más bajo en el concreto con una relación agua/cemento más baja. Se concluye que cuanto menor es la relación agua/cemento, menor es la profundidad de penetración de los cloruros en función del tiempo, resultados esperados, ya que la relación agua/cemento influye directamente en la microestructura del hormigón.

Palabras clave: cloruros; hormigón; método colorimétrico; agua de mar; corrosión.

\section{INTRODUÇÃO}

O concreto é o material mais largamente utilizado na engenharia devido a sua resistência à água, a facilidade de execução de elementos estruturais, em variadas formas e tamanhos, por fim a enorme disponibilidade dos materiais e seu baixo custo. (Mehta e Monteiro, 1994)

Porém, o concreto é falível e em condições de uso frequentemente tornam as armaduras vulneráveis aos processos corrosivos, pela permissão à sua despassivação. (Cascudo e Helene, 2001)

A degradação de estruturas de concreto devido ao problema da corrosão é algo que afeta a construção civil em todo o mundo, com repercussões em função do volume de casos registrados, da precocidade com que ocorrem, bem como do montante de recursos envolvidos.(Meira, 2017)

$\mathrm{O}$ ataque por cloretos é diferente, devido ao fato de que o ponto de ação principal é a corrosão da armadura, e é somente em consequência da corrosão que o concreto circundante é danificado. (Neville, 2016)

A corrosão de armaduras induzida por cloretos, por sua vez, representa uma das manifestações patológicas mais severas que acometem estruturas de concreto armado. Pois, a ação extremamente 
deletéria dos cloretos, que vai desde a despassivação da armadura até a participação plena no processo corrosivo. (Cascudo, 1997)

A relação água/cimento $(\mathrm{a} / \mathrm{c})$ determina a microestrutura das pastas, argamassas e concretos de cimento Portland. A quantidade, forma e distribuição dos poros capilares que em última instância representam o caminho de transporte do ânion cloreto, são decorrentes da relação a/c, da idade e da cura, ou seja, do grau de hidratação dos grãos de cimento. (Helene, 1993)

Dada a influência da relação a/c quanto à penetração de cloretos em concretos de cimento Portland, o presente trabalho busca avaliar essa influência, através do método colorimétrico por aspersão de nitrato de prata em corpos de prova imersos em água do mar.

O método colorimétrico por aspersão de nitrato de prata, se trata de um método qualitativo, vez que não será possível a quantificação de íons cloreto e a conseguinte determinação do teor de cloretos. Pois, baseia-se na aplicação de indicador químico, em que na presença de cloretos, apresenta mudança de cor. (França, 2011)

Este método teve início na Itália, em 1970, foi desenvolvido pelo Dr. Mario Collepardi. (França, 2011)

O método chegou a ser normalizado na Itália. A UNI 7928:1978 "Determinazione della penetrabilità dello ione cloruro", normalizou-o, porém, pela incerteza dos resultados apresentados, foi cancelada sem substituição até o presente momento. (Colombo, 2001 apud França, 2011)

Quando aspergida a solução de nitrato de prata na superfície do concreto, ocorre uma reação fotoquímica. Então, onde há presença de cloretos livres forma-se um precipitado branco de cloreto de prata (1). Nas áreas onde não há cloretos ou que apresentam cloretos combinados, ocorre a formação de um precipitado marrom, que é o óxido de prata. (Silva, 2006; Real et al., 2015)

$$
\mathrm{AgNO}_{3}+\mathrm{Cl}^{-} \rightarrow \mathrm{AgCl} \downarrow+\mathrm{NO}_{3} \Rightarrow \text { branco }
$$

Como as cores branco e marrom são bem contrastantes, é possível distinguir com facilidade as áreas com e sem cloretos livres. Porém, a frente de penetração não é uniforme, sendo necessária a realização de várias medidas ao longo da estrutura ou corpo de prova.

A NT BUILD 492 (1999) recomenda realizar sete medidas a cada $10 \mathrm{~mm}$ devido a não uniformidade da frente de cloretos, sendo o resultado a média entre todas as medidas. No caso de impossibilidade de leitura de alguma das medidas pela presença de agregados, deve-se alterar o ponto de medição ou ignorar esta profundidade se houver outras cinco válidas, de modo a evitar erros grosseiros na leitura da frente de penetração alcançada pelos cloretos. Para evitar o efeito parede, deve-se evitar fazer medidas de profundidade a menos de $10 \mathrm{~mm}$ das bordas.

Ainda é preciso levar em conta que na superfície analisada do concreto, se houver presença de carbonatos também haverá a formação de um precipitado branco, carbonato de prata (2), podendo levar os resultados do método colorimétrico por aspersão de nitrato de prata a acusar falso positivo para a presença de cloretos livres. (Medeiros et al., 2018)

$$
2 \mathrm{Ag}^{+}+\mathrm{CO}_{3}^{2-} \rightarrow \mathrm{Ag}_{2} \mathrm{CO}_{3} \downarrow \Rightarrow \text { branco }
$$

Logo, é necessário verificar se há carbonatação para garantir a validade dos resultados obtidos. De modo que, a aplicação do método colorimétrico por aspesão de nitrato de prata apresente resultados consistentes, a fim de determinar a profundidade da frente de penetração de cloretos em concretos de cimento Portland com diferentes relações a/c. 


\section{PROCEDIMENTO}

A metodologia utilizada para avaliar a profundidade da frente de penetração de cloretos no concreto foi a aplicação do método colorimétrico por aspersão de nitrato de prata em concretos com diferentes relações água/cimento.

Para cumprir tal objetivo, foram confeccionados 18 corpos de prova cilíndricos de concretos, com dimensões 10 × $20 \mathrm{~cm}$, para cada relação a/c escolhida. As relações a/c adotadas foram 0,65 e 0,45, presentes na NBR 6118 (ABNT, 2014) como relações a/c máximas para as classes de agressividade ambiental I e IV, respectivamente.

Portanto, foram moldados 36 corpos de prova (CP's). Cada traço teve os 18 CP's analisados da seguinte forma:

- 6 CP's para ensaiar à compressão axial;

- 6 CP's para avaliar absorção de água;

- 6 CP's para ensaiar à tração por compressão diametral e avaliar frente de cloretos.

Após moldagem dos 36 CP's, os mesmos foram curados ao ar por 28 dias, após este período, 6 CP's de cada concreto foram rompidos a compressão axial. Os 24 CP's restantes foram imersos em água do mar por 60 dias.

Após 60 dias imersos em água do mar, os 24 CP's foram secados em estufa por 3 dias. Desses 24 CP's, 12 CP's foram analisados quanto a absorção de água, os outros 12 CP's foram rompidos à tração por compressão diametral. Após o ensaio de tração por compressão diametral tem-se o CP partido longitudinalmente em duas faces, nessas faces foram aspergidas as soluções para avalição das frentes de cloretos e de carbonatação, uma solução em cada face.

Os CP's foram nomeados da seguinte forma: 1C1 a 1C6 (Concreto 1) e 2C1 a 2C6 (Concreto 2) foram ensaidos absorção por capilaridade, porém os resultados trazidos serão apenas gráficos; $1 \mathrm{C} 7$ a 1C12 (Concreto 1) e 2C7 a 2C12 (Concreto 2) foram aspergidos com as soluções de fenolftaleína e nitrato de prata.

\subsection{Materiais}

\subsubsection{Agregado miúdo}

Tabela 1. Caraterização do agregado miúdo.

\begin{tabular}{|c|c|c|}
\hline \multicolumn{3}{|c|}{ Caracterização do agregado miúdo } \\
\hline \multicolumn{3}{|c|}{ Granulometria do agregado miúdo } \\
\hline Peneiras (mm) & \multicolumn{2}{|c|}{ Porcentagem retida acumulada } \\
\hline 6,3 & \multicolumn{2}{|r|}{0} \\
\hline 4,75 & \multicolumn{2}{|r|}{0} \\
\hline 2,36 & \multicolumn{2}{|r|}{0} \\
\hline 1,18 & \multicolumn{2}{|r|}{1} \\
\hline 0,6 & \multicolumn{2}{|r|}{8} \\
\hline 0,3 & \multicolumn{2}{|r|}{47} \\
\hline 0,15 & \multicolumn{2}{|r|}{93} \\
\hline \multicolumn{2}{|c|}{ Dimensão máxima característica (mm) } & 1,18 \\
\hline \multicolumn{2}{|c|}{ Módulo de finura } & 1,49 \\
\hline \multicolumn{2}{|c|}{ Massa específica $\left(\mathrm{g} / \mathrm{cm}^{3}\right)$} & 2,71 \\
\hline \multicolumn{2}{|c|}{ Massa unitária solta $\left(\mathrm{g} / \mathrm{cm}^{3}\right)$} & 1,51 \\
\hline \multicolumn{2}{|c|}{ Materiais pulverulentos (\%) } & 0,53 \\
\hline \multicolumn{2}{|c|}{ Umidade (\%) } & 0,01 \\
\hline \multicolumn{2}{|c|}{ Absorção de água (\%) } & 0,26 \\
\hline
\end{tabular}


O agregado miúdo utilizado é proveniente de Camaçari, BA. O agregado foi seco ao ar e armazenado em pilha no laboratório. A areia foi ensaiada seguindo as normas de caracterização e distribuição granulométrica.

\subsubsection{Agregado graúdo}

Tabela 2. Caracterização do agregado graúdo.

\begin{tabular}{|c|c|c|}
\hline \multicolumn{3}{|c|}{ Caracterização do agregado graúdo } \\
\hline \multicolumn{3}{|c|}{ Granulometria do agregado graúdo } \\
\hline Peneiras (mm) & \multicolumn{2}{|c|}{ Porcentagem retida acumulada } \\
\hline 19 & \multicolumn{2}{|r|}{0} \\
\hline 12,5 & \multicolumn{2}{|r|}{64} \\
\hline 9,5 & \multicolumn{2}{|r|}{96} \\
\hline 6,3 & \multicolumn{2}{|r|}{100} \\
\hline 4,75 & \multicolumn{2}{|r|}{100} \\
\hline 2,36 & \multicolumn{2}{|r|}{100} \\
\hline 1,18 & \multicolumn{2}{|r|}{100} \\
\hline 0,6 & \multicolumn{2}{|r|}{100} \\
\hline 0,3 & \multicolumn{2}{|r|}{100} \\
\hline 0,15 & \multicolumn{2}{|r|}{100} \\
\hline \multicolumn{2}{|c|}{ Dimensão máxima característica (mm) } & 19 \\
\hline \multicolumn{2}{|c|}{ Módulo de finura } & 6,96 \\
\hline \multicolumn{2}{|c|}{ Massa específica $\left(\mathrm{g} / \mathrm{cm}^{3}\right)$} & 2,79 \\
\hline \multicolumn{2}{|c|}{ Massa unitária solta $\left(\mathrm{g} / \mathrm{cm}^{3}\right)$} & 1,46 \\
\hline \multicolumn{2}{|c|}{ Massa unitária compactada $\left(\mathrm{g} / \mathrm{cm}^{3}\right)$} & 1,56 \\
\hline \multicolumn{2}{|c|}{ Materiais pulverulentos (\%) } & 0,51 \\
\hline \multicolumn{2}{|c|}{ Absorção de água (\%) } & 0,32 \\
\hline
\end{tabular}

O agregado graúdo utilizado é proveniente de Salvador, BA. O agregado foi armazenado em pilha no laboratório. A brita foi ensaiada seguindo as normas de caracterização e distribuição granulométrica.

\subsubsection{Cimento}

O cimento utilizado foi o Cimento Portland composto com fíler, CPII-F-32.

\subsection{4 Água de amassamento}

A água de amassamento foi da rede de abastecimento comum, fornecida pela Empresa Baiana de Águas e Saneamento S.A. (EMBASA).

\subsection{5 Água do mar}

A água do mar utilizada foi coletada na praia de Jardim de Alah, Salvador, Bahia.

\subsubsection{Soluções aspergidas}

Para a avaliação da frente de cloretos foi utilizada uma solução de nitrato de prata a $0,1 \mathrm{~mol} / 1$, como indica NT BUILD 492 (1999). Para a determinação da frente de penetração de cloretos, foram tomadas 7 medidas de cada lado de $20 \mathrm{~cm}$ de uma face fraturada de um CP, portanto foram tomadas 14 medidas de cada CP. 
Para a avaliação da frente de carbonatação foi utilizada uma solução de fenolftaleína a 1\%, como indica a RILEM CPC - 18 (1988). Para a determinação da frente de carbonatação, foram tomadas 3 medidas de cada lado de uma face fraturada de um $\mathrm{CP}$, portanto foram tomadas 12 medidas para cada CP.

As frentes foram medidas com um paquímetro, desprezando $3 \mathrm{~cm}$ de cada extremo, evitando assim o efeito parede.

\subsection{Dosagem e produção dos concretos}

$\mathrm{O}$ método de dosagem utilizado foi o $\mathrm{ABCP} / \mathrm{ACI}$, método da Associação Brasileira de Cimento Portland (ABCP) adaptado do American Concrete Institute (ACI).

Para a dosagem foi fixado um valor de abatimento de 100 a $120 \mathrm{~mm}$ para ambos os concretos. Os concretos com relação a/c de 0,65 e 0,45 foram denominados de Concreto 1 e Concreto 2, respectivamente.

Os corpos de prova confeccionados foram curados ao ar em ambiente de laboratório, protegido de intempéries, porém em área ventilada e não climatizada.

A confecção e moldagem e dos corpos de prova, bem como a realização do Slump test seguiram os procedimentos normativos.

Segue a Tabela 3, com o traço, este em cimento:areia:brita:água, e a resistência média à compressão dos concretos produzidos.

Tabela 3. Caracterização dos concretos.

\begin{tabular}{|c|c|c|c|}
\hline \multicolumn{4}{|c|}{ Concretos produzidos } \\
\hline Concreto & Traço & Abatimento $(\mathrm{mm})$ & Resistência $(\mathrm{MPa})$ \\
\hline Concreto 1 $(\mathrm{a} / \mathrm{c}=0,65)$ & $1: 2,28: 3,57: 0,65$ & 130 & 16,03 \\
\hline Concreto 2 $(\mathrm{a} / \mathrm{c}=0,45)$ & $1: 1,32: 2,47: 0,45$ & 110 & 25,12 \\
\hline
\end{tabular}

\subsection{Imersão em água do mar}

Na Figura 1 abaixo, tem-se o acondicionamento para a imersão dos CP's em água do mar. Devido a disponibilidade de espaço, os CP's foram empilhados para minimizar a variabilidade que isso poderia causar. Os CP's foram trocados de posição aos 30 dias, assim como a água.

Figura 1. Imersão dos CP's em água do mar.

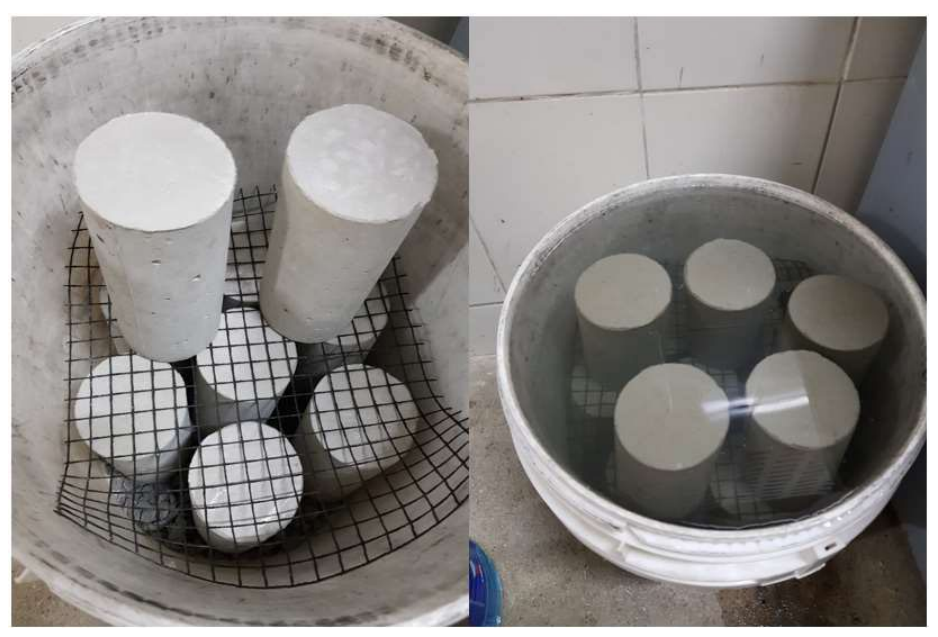


O recipiente foi forrado com uma camada de britas e entre as pilhas de CP's foi usada uma tela plástica. O recipiente foi mantido fechado durante os 60 dias de imersão.

\section{RESULTADOS E DISCUSSÕES}

Antes da apresentação dos resultados é importante salientar que a areia utilizada, com dimensão característica de $1,18 \mathrm{~mm}$, teve a granulometria classificada como abaixo da zona utilizável inferior, sendo assim um agregado não recomendado para uso, conforme NBR 7211 (ABNT, 2009), essa mesma norma numa versão anterior, publicada em 1983, a classificaria como uma areia muito fina. Apesar de um maior teor de finos do agregado miúdo promover uma melhora de algumas das propriedades do concreto como, por exemplo, trabalhabilidade, exsudação e permeabilidade, a melhora dessas propriedades tem um custo, pois, ao melhorar a trabalhabilidade com o alto teor de finos, o concreto exigirá mais água de amassamento, assim exigindo mais cimento para se manter a relação a/c. Por outro lado, essas propriedades só são melhoradas, uma vez que, também há uma boa distribuição granulométrica para garantir uma compacidade, distribuição essa que não se vê no agregado miúdo caracterizado, logo, além de não melhorar significativamente essas propriedades a falta de compacidade produz um concreto menos resistente e durável.

A resistência à compressão do concreto, depende do fator água/cimento, que, por sua vez, depende da distribuição granulométrica do agregado. A distribuição granulométrica deverá ser tal que permita uma mistura de máxima compacidade, compatível com a peça a concretar. (Bauer, 2003) Se a mistura final tiver uma distribuição descontínua, os concretos resultam permeáveis e de baixa trabalhabilidade. (Bauer, 2003)

Não há dúvidas de que a granulometria do agregado seja um fator preponderante para a trabalhabilidade do concreto. A trabalhabilidade, por sua vez, afeta as demandas de água e cimento, controla a segregação, exerce algum efeito na exsudação e influencia o lançamento e o acabamento do concreto. Esses fatores representam importantes características do concreto fresco e também afetam propriedades do concreto endurecido, como resistência, retração e durabilidade. (Neville, 2016)

Para a dosagem dos concretos, foi fixado o abatimento na faixa de 100 a $120 \mathrm{~mm}$ e variou-se a relação água/cimento. Não houve ajustes de traço durante a produção ou testes para se atender a requisitos, pois, não era objetivo do trabalho atender a um fck exigido ou outro parâmetro definido. Os ensaios mecânicos realizados então, serviram a outros ensaios ou mesmo como caracterização dos traços executados.

O ensaio de resistência à compressão axial serviu para avaliar a diferença que a variação na relação água/cimento produziu na resistência do concreto dosado com os materiais utilizados para tal. $\mathrm{O}$ ensaio de resistência à tração por compressão diametral serviu para expor a face interna dos CP's para que se pudesse avaliar as frentes de carbonatação e cloretos, através da aspersão das soluções de fenolftaleína e nitrato de prata respectivamente.

Serão apresentados a seguir, os resultados de absorção de água por capilaridade, que ilustra um pouco a dificuldade que os íons cloretos têm para penetrar os respectivos concretos, os resultados das frentes de carbonatação e frente de penetração de cloretos.

\subsection{Absorção de água e aspectos visuais}

A partir da Figura 2, pode-se observar a capacidade de absorção de ambos os concretos. Essa absorção de água por capilaridade ajuda a ilustrar a capacidade de penetração de cloretos no concreto, através de um dos principais mecanismos de transporte dos cloretos do meio externo para o interior do concreto, que é a absorção. 
Figura 2. Absorção de água por capilaridade de ambos os concretos.

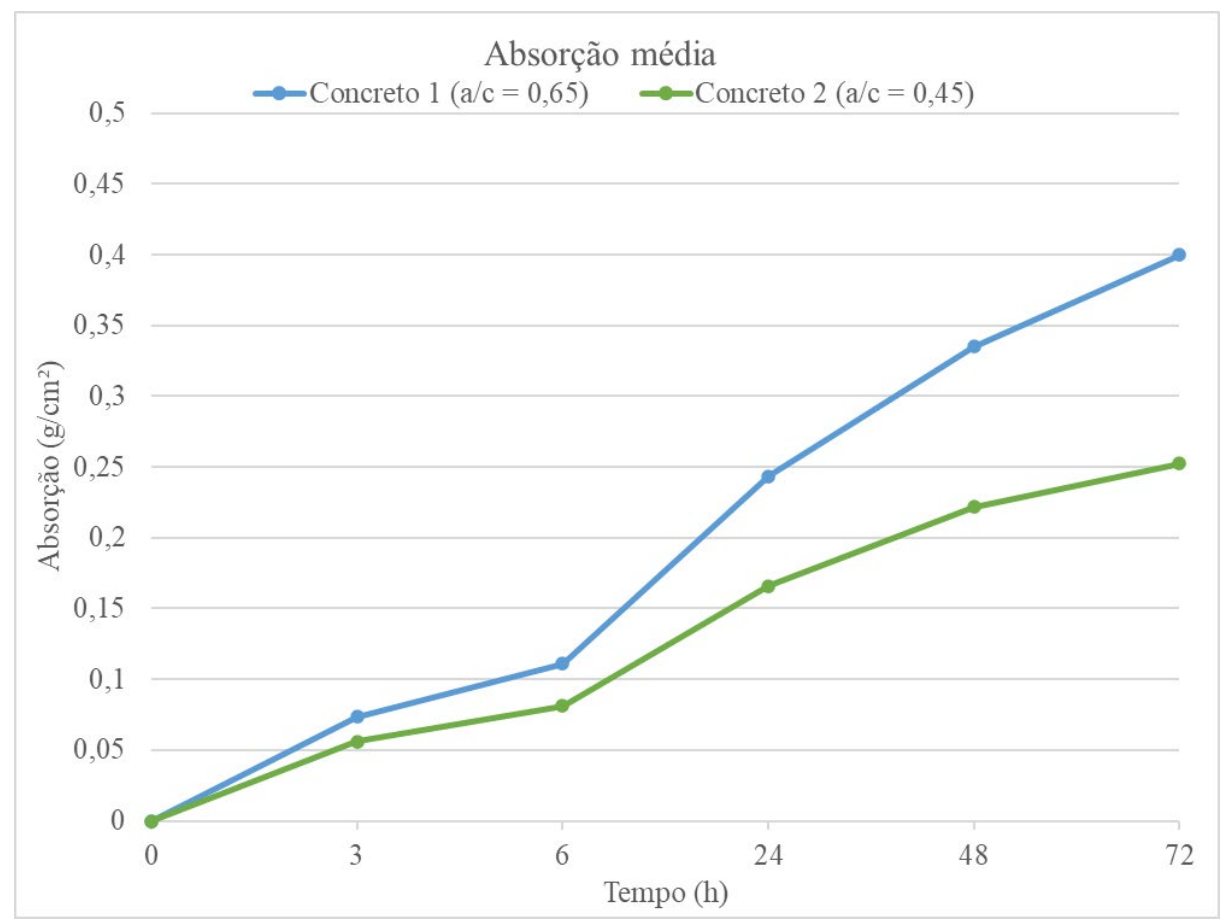

\subsection{Carbonatação}

A partir das Tabelas 4 e 5 abaixo, podemos observar como se deram as frentes de carbonatação em ambos os concretos. E uma ilustração dessas frentes é vista na Figura 3, com fotos de um exemplar de cada concreto.

Figura 3. Solução de fenolftaleína aspergida no CP 1C9 (à esquerda) e no CP 2C11 (à direita).

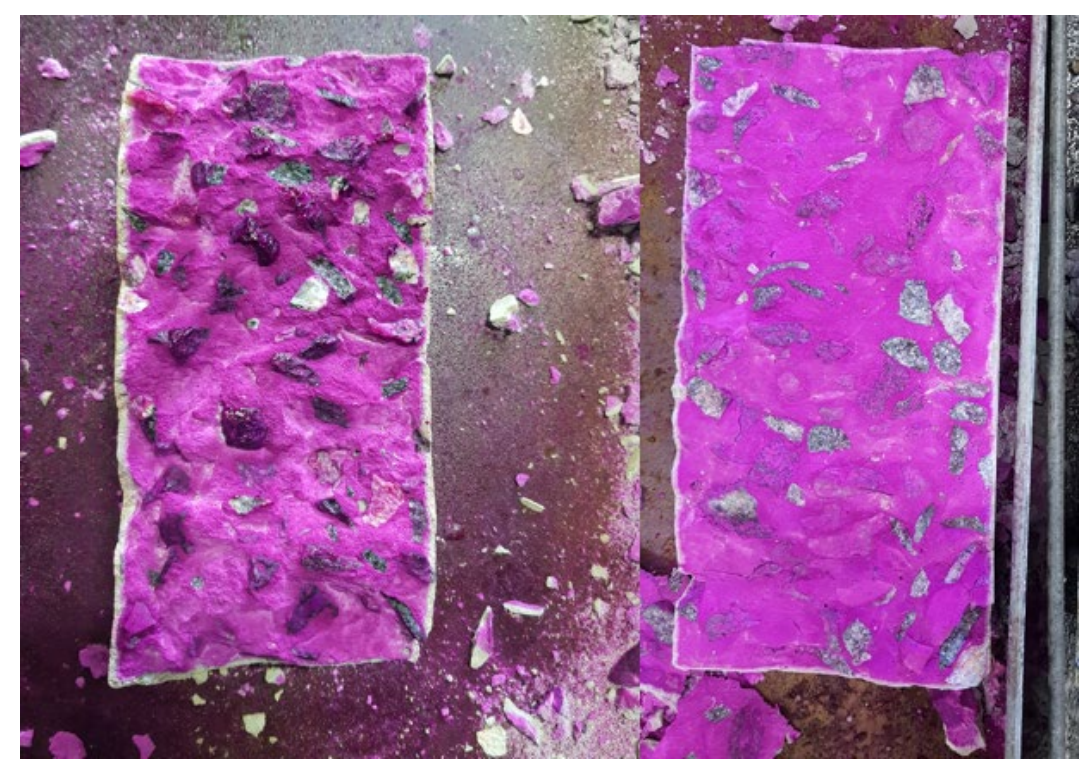


Tabela 4. Medidas da frente de carbonatação do Concreto 1.

\begin{tabular}{|c|c|c|c|c|c|}
\hline \multicolumn{6}{|c|}{ Profundidade de carbonatação do Concreto $1(\mathrm{a} / \mathrm{c}=0,65)$} \\
\hline \multirow{2}{*}{$\mathrm{CP}$} & \multirow{2}{*}{ Lado } & \multicolumn{3}{|c|}{ Medidas (mm) } & \multirow{2}{*}{$\begin{array}{l}\text { Média } \\
(\mathrm{mm})\end{array}$} \\
\hline & & $1^{\mathrm{a}}$ & $2^{\mathrm{a}}$ & $3^{\mathrm{a}}$ & \\
\hline \multirow{4}{*}{$1 \mathrm{C} 7$} & topo & 2,0 & 2,0 & 2,0 & \multirow{4}{*}{1,6} \\
\hline & base & 0,0 & 0,0 & 0,0 & \\
\hline & lado a & 3,0 & 2,0 & 2,0 & \\
\hline & lado b & 2,0 & 2,0 & 2,0 & \\
\hline \multirow{4}{*}{$1 \mathrm{C} 8$} & topo & 2,0 & 2,0 & 2,0 & \multirow{4}{*}{1,5} \\
\hline & base & 0,0 & 0,0 & 0,0 & \\
\hline & lado a & 2,0 & 4,0 & 2,0 & \\
\hline & lado b & 2,0 & 1,0 & 1,0 & \\
\hline \multirow{4}{*}{$1 \mathrm{C} 9$} & topo & 1,0 & 1,0 & 1,0 & \multirow{4}{*}{1,4} \\
\hline & base & 0,0 & 0,0 & 0,0 & \\
\hline & lado a & 2,5 & 2,0 & 2,0 & \\
\hline & lado b & 2,0 & 2,0 & 3,0 & \\
\hline \multirow{4}{*}{$1 \mathrm{C} 10$} & topo & 1,0 & 1,5 & 1,0 & \multirow{4}{*}{1,1} \\
\hline & base & 0,0 & 0,0 & 0,0 & \\
\hline & lado a & 3,0 & 2,0 & 1,5 & \\
\hline & lado b & 1,0 & 1,5 & 1,0 & \\
\hline \multirow{4}{*}{$1 \mathrm{C} 11$} & topo & 2,0 & 2,0 & 1,0 & \multirow{4}{*}{1,6} \\
\hline & base & 0,0 & 0,0 & 0,0 & \\
\hline & lado a & 2,0 & 1,0 & 3,5 & \\
\hline & lado b & 3,0 & 2,0 & 3,0 & \\
\hline \multirow{4}{*}{$1 \mathrm{C} 12$} & topo & 1,0 & 1,0 & 1,0 & \multirow{4}{*}{1,1} \\
\hline & base & 0,0 & 0,0 & 0,0 & \\
\hline & lado a & 1,0 & 2,0 & 1,5 & \\
\hline & lado b & 3,0 & 1,0 & 2,0 & \\
\hline \multicolumn{5}{|c|}{ Profundidade média de carbonatação do Concreto 1 (mm) } & 1.4 \\
\hline
\end{tabular}

Tabela 5. Medidas da frente de carbonatação do Concreto 2.

\begin{tabular}{|c|c|c|c|c|c|}
\hline \multicolumn{6}{|c|}{ Profundidade de carbonatação do Concreto $2(\mathrm{a} / \mathrm{c}=0,45)$} \\
\hline \multirow{2}{*}{$\mathrm{CP}$} & \multirow{2}{*}{ Lado } & \multicolumn{3}{|c|}{ Medidas (mm) } & \multirow{2}{*}{$\begin{array}{l}\text { Média } \\
(\mathrm{mm})\end{array}$} \\
\hline & & $1^{\mathrm{a}}$ & $2^{\mathrm{a}}$ & $3^{\mathrm{a}}$ & \\
\hline \multirow{4}{*}{$2 \mathrm{C} 7$} & topo & 0,5 & 0,5 & 0,5 & \multirow{4}{*}{0,5} \\
\hline & base & 0,0 & 0,0 & 0,0 & \\
\hline & lado a & 0,5 & 0,0 & 0,5 & \\
\hline & lado b & 1,5 & 1,0 & 1,0 & \\
\hline \multirow{4}{*}{$2 \mathrm{C} 8$} & topo & 0,0 & 0,0 & 0,0 & \multirow{4}{*}{0,0} \\
\hline & base & 0,0 & 0,0 & 0,0 & \\
\hline & lado a & 0,0 & 0,0 & 0,0 & \\
\hline & lado b & 0,0 & 0,0 & 0,0 & \\
\hline \multirow{4}{*}{$2 \mathrm{C} 9$} & topo & 0,0 & 0,0 & 0,0 & \multirow{4}{*}{0,1} \\
\hline & base & 0,0 & 0,0 & 0,0 & \\
\hline & lado a & 0,5 & 0,0 & 0,0 & \\
\hline & lado b & 0,0 & 0,5 & 0,0 & \\
\hline \multirow{4}{*}{$2 \mathrm{C} 10$} & topo & 0,0 & 1,0 & 0,0 & \multirow{4}{*}{0,6} \\
\hline & base & 0,0 & 0,0 & 0,0 & \\
\hline & lado a & 2,0 & 0,5 & 0,5 & \\
\hline & lado b & 0.5 & 2,0 & 0.5 & \\
\hline \multirow{4}{*}{$2 \mathrm{C} 11$} & topo & 0,5 & 0,5 & 0,5 & \multirow{4}{*}{0,4} \\
\hline & base & 0,0 & 0,0 & 0,0 & \\
\hline & lado a & 0,5 & 0,5 & 0,5 & \\
\hline & lado b & 0,5 & 0,5 & 0,5 & \\
\hline \multirow{4}{*}{$2 \mathrm{C} 12$} & topo & 0,0 & 0,5 & 0,0 & \multirow{4}{*}{0,3} \\
\hline & base & 0,0 & 0,0 & 0,0 & \\
\hline & lado a & 0,5 & 0,5 & 0,5 & \\
\hline & lado b & 0,5 & 0,5 & 0,5 & \\
\hline \multicolumn{5}{|c|}{ Profundidade média de carbonatação do Concreto $2(\mathrm{~mm})$} & 0,3 \\
\hline
\end{tabular}


Houve uma carbonatação média de $1,4 \mathrm{~mm}$ para o Concreto 1 e $0,3 \mathrm{~mm}$ para o Concreto 2. Sempre houve pelo menos um dos lados de $10 \mathrm{~cm}$ sem frente de carbonatação alguma. Portanto, houve uma proteção à base de cada CP. Buscando minimizar essa distorção e trazer dados mais fidedignos, foram desprezadas as medidas da base de cada CP e então calculadas novas médias de frente de carbonatação, apesar da RILEM CPC - 18 (1988) indicar a tomada de medidas por todos os lados. Segue Tabela 6 abaixo, com a frente de carbonatação média de cada concreto, desprezando-se a base.

Tabela 6. Frente de carbonatação, desprezando-se a base.

\begin{tabular}{|c|c|}
\hline \multicolumn{2}{|c|}{ Frente de carbonatação média desprezando a base } \\
\hline Concreto & Carbonatação $(\mathrm{mm})$ \\
\hline Concreto $1(\mathrm{a} / \mathrm{c}=0,65)$ & 1,9 \\
\hline Concreto $2(\mathrm{a} / \mathrm{c}=0,45)$ & 0,4 \\
\hline
\end{tabular}

\subsection{Penetração de Cloretos}

A partir das Tabelas 7 e 8 abaixo, podemos observar como se deram as frentes de penetração de cloretos em ambos os concretos. E uma ilustração dessas frentes é vista na Figuras 4, com fotos de um exemplar de cada concreto.

Figura 4. Solução de nitrato de prata aspergida no CP 1C7 (à esquerda) e CP 2C11 (à direita).

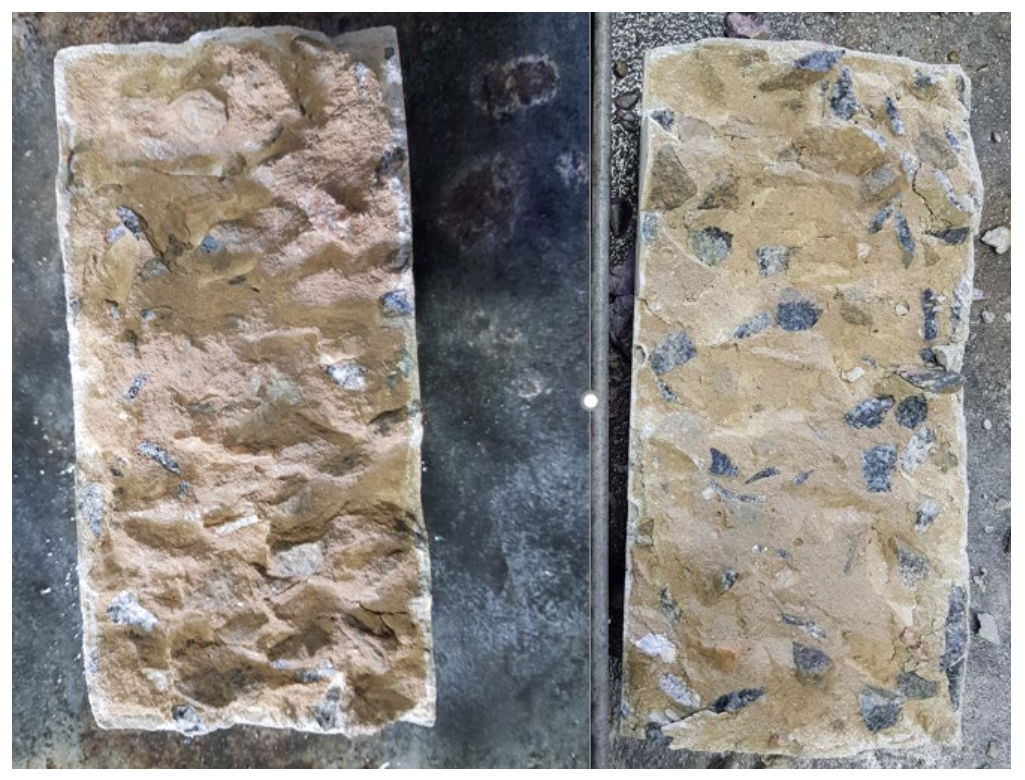


Tabela 7. Medidas da frente de penetração de cloretos do Concreto 1.

\begin{tabular}{|c|c|c|c|c|c|c|c|c|c|c|c|c|}
\hline \multicolumn{13}{|c|}{ Frente de penetração de cloretos no Concreto $1(\mathrm{a} / \mathrm{c}=0,65)$} \\
\hline$\overline{\mathrm{CP}}$ & \multicolumn{2}{|c|}{$\overline{1 C 7}$} & \multicolumn{2}{|c|}{$1 \mathrm{C} 8$} & \multicolumn{2}{|c|}{$1 \mathrm{C} 9$} & \multicolumn{2}{|c|}{$1 \mathrm{C} 10$} & \multicolumn{2}{|c|}{$\overline{1 \mathrm{C} 11}$} & \multicolumn{2}{|c|}{$1 \mathrm{C} 12$} \\
\hline Medidas & \begin{tabular}{|c|}
$\begin{array}{c}\text { Lado A } \\
(\mathrm{mm})\end{array}$ \\
\end{tabular} & $\begin{array}{c}\begin{array}{c}\text { Lado B } \\
\text { (mm) }\end{array} \\
\end{array}$ & \begin{tabular}{|c|} 
Lado A \\
$(\mathrm{mm})$
\end{tabular} & \begin{tabular}{|c|}
$\begin{array}{c}\text { Lado B } \\
(\mathrm{mm})\end{array}$ \\
\end{tabular} & $\begin{array}{c}\text { Lado A } \\
\text { (mm) }\end{array}$ & \begin{tabular}{|c|} 
Lado B \\
$(\mathrm{mm})$ \\
\end{tabular} & $\begin{array}{c}\text { Lado A } \\
(\mathrm{mm})\end{array}$ & \begin{tabular}{|c|}
$\begin{array}{c}\text { Lado B } \\
(\mathrm{mm})\end{array}$ \\
\end{tabular} & \begin{tabular}{|c|} 
Lado A \\
$(\mathrm{mm})$ \\
\end{tabular} & \begin{tabular}{|c|}
$\begin{array}{c}\text { Lado B } \\
(\mathrm{mm})\end{array}$ \\
\end{tabular} & \begin{tabular}{|c|}
$\begin{array}{c}\text { Lado A } \\
(\mathrm{mm})\end{array}$ \\
\end{tabular} & \begin{tabular}{|c}
$\begin{array}{c}\text { Lado B } \\
(\mathrm{mm})\end{array}$ \\
\end{tabular} \\
\hline $1^{\mathrm{a}}$ & $\overline{3,5}$ & 4,9 & $\overline{2,5}$ & $\overline{4,3}$ & 3,2 & 3,2 & $\overline{4,0}$ & $\overline{3,6}$ & $\overline{4,0}$ & $\overline{4,2}$ & $\overline{3,5}$ & $\overline{4,3}$ \\
\hline $2^{\mathrm{a}}$ & 2,9 & 5,9 & 3,5 & 3,3 & 4,5 & 4,0 & 4,0 & 4,1 & 3,0 & 5,6 & 3,5 & 4,5 \\
\hline $3^{\mathrm{a}}$ & 2,3 & 3,5 & 3,0 & 2,5 & 5,2 & 2,5 & 3,5 & 3,5 & 3,6 & 3,5 & 3,5 & 5,0 \\
\hline $4^{\mathrm{a}}$ & 4,0 & 3,3 & 5,0 & 7,0 & 2,6 & 2,5 & 4,0 & 3,0 & 2,5 & 4,0 & 3,0 & 4,0 \\
\hline $5^{a}$ & 3,0 & 3,9 & 3,5 & 3,0 & 1,8 & 2,2 & 3,5 & 4,5 & 4,0 & 4,6 & 2,0 & 3,0 \\
\hline $6^{\mathrm{a}}$ & 3,0 & 3,0 & 4,9 & 4,3 & 2,3 & 1,6 & 3,3 & 3,8 & 3,3 & 4,0 & 3,0 & 3,0 \\
\hline $7^{\mathrm{a}}$ & 3,8 & 6,0 & 3,3 & 2,8 & 3,0 & 1,5 & 3,0 & 3,1 & 5,6 & 4,0 & 4,0 & 5,4 \\
\hline Média $(\mathrm{mm})$ & \multicolumn{2}{|c|}{3,8} & \multicolumn{2}{|c|}{3,8} & \multicolumn{2}{|c|}{2,9} & \multicolumn{2}{|c|}{3,6} & \multicolumn{2}{|c|}{4,0} & \multicolumn{2}{|c|}{$\begin{array}{l}1 \\
3,7\end{array}$} \\
\hline \multicolumn{13}{|c|}{ Profundidade média da frente de penetração de cloretos no Concreto $1(\mathrm{~mm})$} \\
\hline & & & & & & 3,6 & & & & & & \\
\hline
\end{tabular}

Tabela 8. Medidas da frente de penetração de cloretos do Concreto 2.

\begin{tabular}{|c|c|c|c|c|c|c|c|c|c|c|c|c|}
\hline \multicolumn{13}{|c|}{ Frente de penetração de cloretos no Concreto $2(\mathrm{a} / \mathrm{c}=0,45)$} \\
\hline$\overline{\mathrm{CP}}$ & \multicolumn{2}{|c|}{$2 \mathrm{C7}$} & \multicolumn{2}{|c|}{$2 \mathrm{C} 8$} & \multicolumn{2}{|c|}{$2 \mathrm{C} 9$} & \multicolumn{2}{|c|}{$2 \mathrm{C} 10$} & \multicolumn{2}{|c|}{$2 \mathrm{C} 11$} & \multicolumn{2}{|c|}{$2 \mathrm{C} 12$} \\
\hline Medidas & $\begin{array}{c}\text { Lado A } \\
(\mathrm{mm})\end{array}$ & $\begin{array}{c}\text { Lado B } \\
(\mathrm{mm})\end{array}$ & $\begin{array}{c}\text { Lado A } \\
(\mathrm{mm})\end{array}$ & \begin{tabular}{|c|}
$\begin{array}{c}\text { Lado B } \\
(\mathrm{mm})\end{array}$ \\
\end{tabular} & $\begin{array}{c}\text { Lado A } \\
(\mathrm{mm})\end{array}$ & \begin{tabular}{|c|} 
Lado B \\
$(\mathrm{mm})$
\end{tabular} & $\begin{array}{c}\text { Lado A } \\
(\mathrm{mm})\end{array}$ & \begin{tabular}{|c|}
$\begin{array}{c}\text { Lado B } \\
(\mathrm{mm})\end{array}$ \\
\end{tabular} & $\begin{array}{c}\text { Lado A } \\
(\mathrm{mm})\end{array}$ & \begin{tabular}{|c|}
$\begin{array}{c}\text { Lado B } \\
(\mathrm{mm})\end{array}$ \\
\end{tabular} & $\begin{array}{c}\text { Lado A } \\
(\mathrm{mm})\end{array}$ & $\begin{array}{c}\text { Lado B } \\
\text { (mm) }\end{array}$ \\
\hline $1^{\mathrm{a}}$ & $\overline{1,9}$ & $\overline{1,0}$ & $\overline{1,5}$ & 1,0 & 1,8 & 1,2 & 0,4 & 0,9 & 2,0 & 1,0 & 0,9 & 0,9 \\
\hline $2^{\mathrm{a}}$ & 0,9 & 1,0 & 1,5 & 1,1 & 1,0 & 1,5 & 0,4 & 0,4 & 1,6 & 1,0 & 0,9 & 1,1 \\
\hline $3^{\mathrm{a}}$ & 2,1 & 0,8 & 0,9 & 0,9 & 1,0 & 1,5 & 0,4 & 0,4 & 1,0 & 1,0 & 0,9 & 1,1 \\
\hline $4^{\mathrm{a}}$ & 1,8 & 0,5 & 0,8 & 1,6 & 1,0 & 0,8 & 0,4 & 0,4 & 0,5 & 0,5 & 0,9 & 1,1 \\
\hline $5^{a}$ & 1,3 & 0,5 & 0,5 & 1,6 & 0,5 & 0,5 & 0,4 & 0,4 & 0,5 & 0,5 & 0,7 & 0,9 \\
\hline $6^{\mathrm{a}}$ & 0,8 & 0,4 & 0,4 & 1,3 & 1,1 & 0,5 & 0,4 & 0,4 & 1,8 & 0,4 & 0,7 & 1,1 \\
\hline $7^{a}$ & 0,9 & 0,4 & 1,5 & 1,1 & 0,4 & 0,5 & 0,4 & 0,4 & 0,8 & 0,3 & 1,0 & 1,1 \\
\hline Média $(\mathrm{mm})$ & \multicolumn{2}{|c|}{1,0} & \multicolumn{2}{|c|}{1,1} & \multicolumn{2}{|c|}{1,0} & \multicolumn{2}{|c|}{0,4} & \multicolumn{2}{|c|}{0,9} & \multicolumn{2}{|c|}{1,0} \\
\hline \multicolumn{13}{|c|}{ Profundidade média da frente de penetração de cloretos no Concreto $2(\mathrm{~mm})$} \\
\hline & & & & & & 0,9 & & & & & & \\
\hline
\end{tabular}

Tabela 9. Frente média de cloretos e carbonatação.

\begin{tabular}{|c|c|c|}
\hline \multicolumn{3}{|c|}{ Resumo de frentes de cloretos e carbonatação } \\
\hline Concreto & $\begin{array}{c}\text { Cloretos } \\
(\mathrm{mm})\end{array}$ & $\begin{array}{c}\text { Carbonatação } \\
(\mathrm{mm})\end{array}$ \\
\hline Concreto $1(\mathrm{a} / \mathrm{c}=0,65)$ & 3,6 & 1,9 \\
\hline Concreto $2(\mathrm{a} / \mathrm{c}=0,45)$ & 0,9 & 0,4 \\
\hline
\end{tabular}

Os resultados obtidos foram de uma frente de penetração de cloretos de 3,6 mm no Concreto 1 e $0,9 \mathrm{~mm}$ no Concreto 2, uma diferença $2,7 \mathrm{~mm}$ entre as frentes, ou ainda, uma frente 4 vezes maior no Concreto 1 em relação ao Concreto 2. 
Uma carbonatação pode sugerir um falso positivo no uso da solução indicadora de nitrato de prata para determinação da profundidade de penetração de cloretos no concreto. (Medeiros et al., 2018) No entanto, a profundidade desta frente de carbonatação não é suficiente para interferir na avaliação da profundidade atingida pela penetração de cloretos nos dois concretos, visto que a diferença das frentes foi discrepante. Por fim, as condições as quais os corpos de prova foram expostos não promoveu o avanço da carbonatação, uma vez que, os corpos de prova ficaram na maior parte do tempo imersos em água do mar.

Se os poros do concreto estão saturados, a carbonatação também não avança porque a difusão do $\mathrm{CO}_{2}$ na água é $10^{4}$ vezes mais lenta do que no ar. (Meira, 2017)

A influência da relação água/cimento na capacidade de penetração dos íons cloreto é crucial, vez que, dentre os fatores que influenciam a corrosão induzida por cloretos, como por exemplo, cura, temperatura, fissuras, tipo de cimento, entre outros, o único que houve variação foi a relação água/cimento e logicamente sua influência na permeabilidade e absorção dos respectivos concretos. Ambos os concretos foram submetidos as mesmas condições desde a sua produção até a realização dos ensaios, desta forma, outros aspectos que poderiam influenciar na profundidade de penetração de cloretos são minimizados e a maior causa destes resultados obtidos são por consequência da respectiva relação água/cimento de cada concreto.

É fato que a relação água/cimento é diretamente proporcional a resistência do concreto e tem uma relevante contribuição para a microestrutura do concreto, desta forma, influenciando a permeabilidade e absorção.

A resistência costuma fornecer uma ideia geral da qualidade do concreto, visto que está diretamente relacionada à estrutura da pasta de cimento hidratada. (Neville, 2016)

Resistência e permeabilidade da pasta de cimento hidratada são dois lados da mesma moeda, uma vez que ambos estão estreitamente relacionados à porosidade capilar ou à relação sólido/espaço. (Mehta e Monteiro, 1994)

Sendo assim, a relação água/cimento tem grande influência nos poros e capilares do concreto, e estes são de extrema relevância para a inserção dos cloretos no concreto, ou ainda, para o transporte dos cloretos dentro do concreto. O tamanho dos poros tem influência na absorção e permeabilidade, quanto maior menor a absorção, porém tem efeito contrário à permeabilidade, e principalmente a comunicação entre os poros garante o transporte dentro do concreto, além de outros fatores como tipo de cimento, grau de hidratação do cimento, condições de exposição, entre outros.

Segue abaixo as imagens de todos os CP's e suas frentes de cloretos e carbonatação. 
Figura 5. Da esquerda para direita: $1 \mathrm{C} 7,1 \mathrm{C} 8,1 \mathrm{C} 9,1 \mathrm{C} 10,1 \mathrm{C} 11$ e $1 \mathrm{C} 12$.



Figura 6. Da esquerda para direita: 2C7, 2C8, 2C9, 2C10, 2C11 e $2 \mathrm{C} 12$.

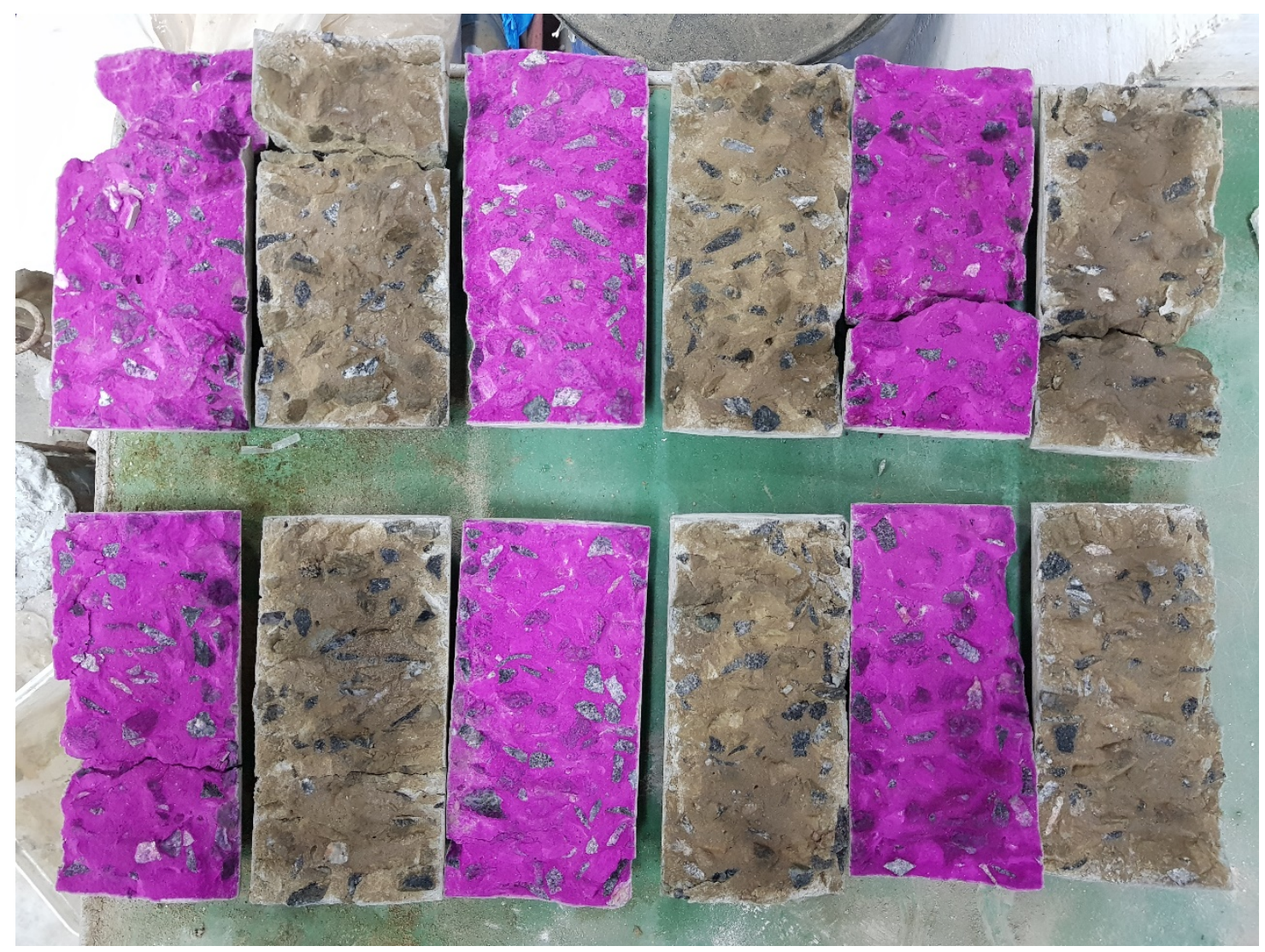




\section{CONCLUSÕES}

Os resultados obtidos foram de uma frente de penetração de cloretos menor no concreto com menor relação água/cimento.

Apesar do acréscimo de resistência ter sido baixo entre os concretos com relação água/cimento de 0,65 e 0,45 , a sua diferença de relação água/cimento de 0,20 proporcionou uma diferença de $300 \%$ entre as profundidades das frentes de penetração de cloretos, e uma diferença de $375 \%$ entre as profundidades das frentes de carbonatação. Resultados já esperados, visto que a relação água/cimento é inversamente proporcional a resistência e a resistência, por sua vez, depende da fase sólida do concreto, ou seja, temos uma menor porosidade e uma microestrutura mais compacta nos concretos com menor relação água/cimento, frente a concretos com maior relação água/cimento e utilizando os mesmos materiais. Claro que a compacidade dos concretos depende de outros fatores, mas neste trabalho a maior influência vem da relação água/cimento. Assim os resultados nos mostram que o concreto com menor relação água/cimento tem maior resistência a penetração de cloretos, e isso só é possível com uma menor porosidade e desde que essa menor porosidade também resulte numa menor intercomunicação entre os poros.

Pode-se destacar ainda, que o método colorimétrico por aspersão de nitrato de prata apresentou resultados consistentes, visto que, foi de fácil aplicação e leitura da frente de penetração de cloretos para concretos expostos a cloretos e ainda carbonatados em menor grau. Porém, deve-se ter cuidado na avaliação de concretos somente carbonatados, ou pelo menos, concretos com alto grau de carbonatação.

\section{REFERÊNCIAS}

Associação Brasileira de Normas Técnicas. (2003). NBR NM 248: Agregados - Determinação da composição granulométrica. Rio de Janeiro.

Associação Brasileira de Normas Técnicas. (2003). NBR NM 46: Agregados - Determinação do material fino que passa através da peneira $75 \mu \mathrm{m}$, por lavagem. Rio de Janeiro.

Associação Brasileira de Normas Técnicas. (2006). NBR NM 45: Agregados - Determinação da massa unitária e do volume de vazios. Rio de Janeiro.

Associação Brasileira de Normas Técnicas. (2009). NBR NM 52: Agregado miúdo - Determinação de massa específica e massa específica aparente. Rio de Janeiro.

Associação Brasileira de Normas Técnicas. (2009). NBR NM 53: Agregado graúdo - Determinação de massa especifica, massa específica aparente e absorção de água. Rio de Janeiro.

Associação Brasileira de Normas Técnicas. (2009). NBR 7211: Agregados para concreto Especificação. Rio de Janeiro.

Associação Brasileira de Normas Técnicas. (2014). NBR 6118: Projeto de estruturas de concreto - Procedimento. Rio de Janeiro.

Associação Brasileira de Normas Técnicas. (2015). NBR 5738: Concreto - Procedimentos para moldagem e cura de corpos de prova. Rio de Janeiro.

Associação Brasileira de Normas Técnicas. (2015). NBR 12655: Concreto de cimento PortlandPreparo, controle, recebimento e aceitação. Rio de Janeiro.

Associação Brasileira de Normas Técnicas. (2018). NBR 5739: Concreto - Ensaio de compressão de corpos de prova cilíndricos. Rio de Janeiro.

Associação Brasileira de Normas Técnicas. (2020). NBR 16889: Concreto - Determinação da consistência pelo abatimento do tronco de cone. Rio de Janeiro.

Bauer, L. A. F. (2003), "Materiais de construção 1: concreto, madeira, cerâmica, metais, plásticos, asfalto - novos materiais para construção civil'. LTC, Rio de Janeiro. 
Cascudo, O. (1997), "O controle da corrosão de armaduras em concreto: inspeção e técnicas eletroquímicas”. PINI, São Paulo; Editora UFG, Goiânia, Brasil.

Cascudo, O., Helene, P. R. L. (2001), "Resistência à corrosão no concreto dos tipos de armaduras brasileiras para concreto armado". EPUSP, São Paulo, Brasil, 20p.

França, C. B. (2011), "Avaliação de cloretos livres em concretos pelo método de aspersão de solução de nitrato de prata", Dissertação de Mestrado, Universidade Católica de Pernambuco.

Helene, P. R. L. (1993), "Contribuição ao estudo da corrosão em armaduras de concreto armado", Tese de livre docência, Universidade de São Paulo.

Medeiros, M. H. F., Réus, G. C., Pontes, C. V. (2018). "Nitrato de prata como método colorimétrico para detecção da penetração de cloretos: análise crítica", $3^{\circ}$ Simpósio Paranaense de Patologia das Construções (3 SPPC), artigo 3SPPC1017, pp. 186-197. DOI: 10.4322/25267248.017

Mehta, P. K., Monteiro, P. J. M. (1994), “Concreto: estrutura, proriedades e materiais”. PINI, São Paulo, Brasil, 573p.

Meira, G. R. (2017), “Corrosão de armaduras em estruturas de concreto: fundamentos, diagnóstico e prevenção". IFPB, João Pessoa, 130p.

Neville, A. M. (2016), "Propriedades do concreto". Tradução: Ruy Alberto Cremonini. 5. ed. Bookman, Porto Alegre.

NORDTEST METHOD. (1999). NT BUILD 492: Concrete, mortar and cement-based repair: chloride migration coeficiente from non-steady-state migration experiments. Finlândia.

Real, L. V., Oliveira, D. R. B., Soares, T., Medeiros, M. H. F. (2009), Método colorimétrico por aspersão de nitrato de prata para avaliação da penetração de cloretos em concreto: estado da arte. Revista ALCONPAT. 5(2):149-159. http://dx.doi.org/10.21041/ra.v5i2.84

RILEM Recommendations. (1988). CPC - 18: Measurent of hardened concrete carbonation depth. Pp. 453-455.

Silva, F. G. (2006), "Estudo de concretos de alto desempenho frente à ação de cloretos", Tese de Doutorado, Universidade de São Paulo. 